\title{
A IMPORTÂNCIA DA PESCA COM TIMBÓ PARA O POVO INDÍGENA APYÃWA (TAPIRAPÉ) DE MATO GROSSO
}

\author{
Xawapa'io Tapirapé ${ }^{1}$, Marcelo Franco Leão ${ }^{2}$
}

Resumo: A pesca artesanal com o cipó timbó é bastante recorrente entre os povos indígenas. Porém, cada etnia tem seu modo de bater timbó, bem como suas tradições e costumes. Esse estudo etnográfico teve o objetivo de registrar a pesca com timbó e sua importância para o povo Tapirapé. Seu desenvolvimento ocorreu durante os anos de 2014, 2015 e 2016 na aldeia Tapiparanytãwa (córrego da onça), localizada em Confresa/ MT. A pesca pode feita por homens e mulheres que ao utilizar esse cipó venenoso, diluindo seu látex na água, asfixia peixes que sobem para superfície, tornando mais fácil capturá-los. Essa substância não é tóxica para animais de sangue quente, porém pode causar irritação nos olhos quando alguém for se banhar nas águas onde o timbó foi batido. Cabe lembrar que o cipó timbó só provoca efeito quando golpear pancadas em pedaços de seu caule sobre a água. A partir daí o trabalho realizado é o de apanhar os peixes que estão atordoados ou mortos e flutuando. Também pode fechar o igarapé fazendo uma barragem para esperar o peixe passar. Os peixes que afundam são perdidos, pois não podem ser capturados em águas profundas. A pesca com o timbó faz parte de ritual sagrado para a etnia Tapirapé. Essa tradição está inserida na vida do povo indígena, nos seus costumes, em sua cultura e tradições, por isso precisa ser respeitada e preservada.

Palavras-chave: Pesca coletiva. Cultura indígena. Povo tradicional.

1 Graduação em Pedagogia pela Faculdade Indígena Intercultural da Universidade do Estado de Mato Grosso (UNEMAT). Professor na escola indígena da comunidade Urubu Branco, Confresa-MT.

2 Doutorado em andamento em Educação em Ciências (UFRGS). Mestrado em Ensino (Univates). Graduação em Química (UNISC) e em Física (UNEMAT). Pós-graduação em Orientação Educacional (Dom Alberto) e em Relações Raciais na Educação e na sociedade Brasileira (UFMT). Foi professor na Faculdade Indígena Intercultural da Universidade do Estado de Mato Grosso (UNEMAT). Atualmente é professor do IFMT Campus Confresa. 


\section{INTRODUÇÃO}

O povo Apyãwa (ou Tapirapé como conhecido pelo não indígena) é uma nação que pertence ao tronco linguístico Tupi-Guarani, que habita na área indígena Urubu-Branco que abrange os municípios de Santa Teresinha, Porto Alegre do Norte e Confresa, região norte do estado Mato Grosso, onde exerce grande expressão na sociedade envolvente.

Esse povo tradicional está distribuídos em duas áreas Indígenas: Uma, denominada de terra indígena Tapirapé/Karajá, pertence ao Município de Santa Terezinha, no Estado de Mato Grosso, e nela se encontra uma das aldeias denominada de Majtyri; A outra área é a terra indígena Urubu Branco, onde estão localizadas 7 (sete) Aldeias, que são: Tapi'itawa, Akara'ytawa (Santa Laura), Towajaatãwa (Sapeva), Wiriaotawa (Codebra), Tapiparanytawa (Córrego da Onça), Myryxitãwa (Buriti) e a Inataotãwa (Santa luzia), esta última que foi fundada no ano passado, ano de 2013.

A população atual nas 7 (sete) aldeias é de cerca de 850 habitantes. Como já mencionado, a língua falada pelo nosso povo é do Tronco linguístico Tupi e pertence à família do Tupi-Guarani. Existem várias etnias que pertencem à mesma família e que fala palavras semelhantes às do nosso povo, sendo algumas das etnias: Kamaiurá, Kayabi, Guajajara e outros mais que falam línguas parecidas com a que falamos (ISA, 1996).

A temática eleita nesse estudo é a importância da pesca com timbó para o povo Apyâwwa, por isso esta pesquisa investiga a origem e as características do cipó timbó, bem como conhecer o processo de preparação do xigy (nome do timbó na língua materna). Neste sentido, a escolhida se deu por ser uma forma de registrar pela escrita este aspecto cultural afim de que as futuras gerações possam estudar e conhecer o tema na sala de aula e na comunidade.

Trata-se de um resgate histórico, até mesmo porque o pesquisador é um indígena de não muita idade e precisa também conhecer os saberes que os antepassados deixaram, como eles agiam, quais as regras e de que maneira o povo Apyãwa utilizava o timbó para matar peixes. Ainda hoje se pratica esta atividade de pesca coletiva com o timbó, por isso este estudo é de extrema importância para registrar a cultura indígena e possibilitar que as crianças estudem sobre esta prática.

Diante do exposto, o estudo teve como objetivo geral registrar a pesca tradicional com timbó e sua importância para o povo Tapirapé. Para tanto, foi necessário entrevistar mais experiente dessa comunidade tradicional sobre o xigy para saber como ele surgiu segundo o povo Apyãwa, bem como as regras que envolvem a pesca e saber como que preparo o peixe, fazer pesquisas nos estudos sobre o tema e observar a realização de uma pesca coletiva para registrar os momentos e realizar anotações e entrevistas no caderno de campo.

Este estudo é parte do Trabalho de Conclusão de Curso de Pedagogia ofertado pela Faculdade Intercultural Indígena da Universidade do Estado 
de Mato Grosso (UNEMAT), o qual foi defendido em 2016. Para melhor organizar este texto, na sequência é apresentada uma breve reflexão sobre a pesca tradicional para o povo indígena, seguido dos caminhos metodológicos adotados nesse estudo e por fim são apresentados os resultados da investigação em si que envolvem as regras, o antes, durante e depois da pesca, o envolvimento do povo e o preparo do alimento capturado, além da relação dessa prática com o meio ambiente.

\section{ALGUMAS REFLEXÕES SOBRE A PESCA TRADICIONAL}

A pesca tradicional é aquela praticada com instrumentos da tecnologia tradicional indígena (SILVA, 2012). Ela faz parte da cultura indígena que realiza essa prática com a flecha, também pegaram o peixe com a peneira e no outro artesanato que nos usava para pesca. A Figura 1 ilustra que essa prática cultural é exercida por todos, desde pequenos. A pesca com o timbó é outra prática bastante recorrente entre os povos indígenas (OLIVEIRA,2015). Essa é uma prática tradicional também cultivada pelo povo Tapirapé.

Figura 1: As crianças aprendem desde novos os costumes do povo

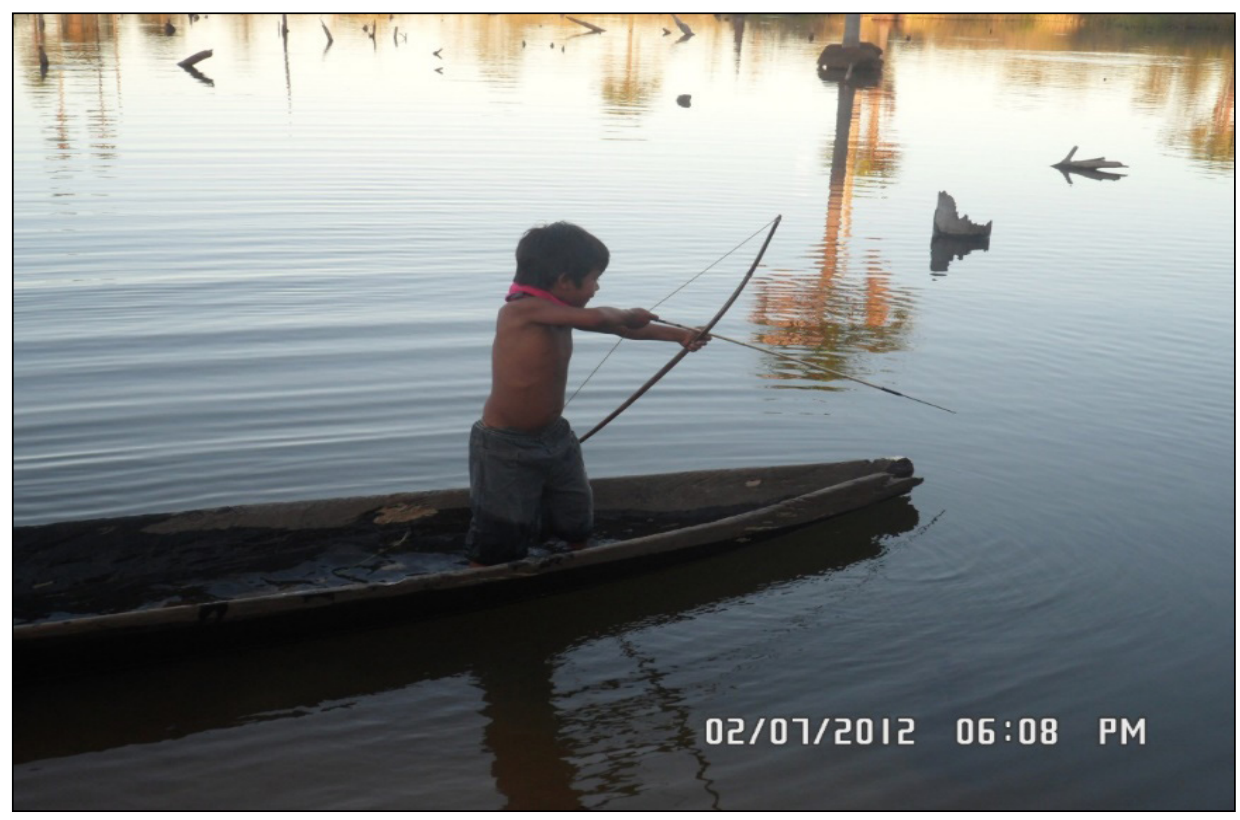

Fonte: Acervo pessoal do pesquisador (2014).

O timbó na comunidade da aldeia Córrego da Onça é uma planta classificada como cipó e somente pode ser encontrada no meio do mato. Existem dois tipos de timbó a saber: tem o maior e mais grosso e um outro tipo mais fino e espeço. Esses dois tipos de cipó são usados juntos pelo povo 
Tapirapé para potencializar a ação de seu veneno. Eles são cipó que pode ser usado nos lagos. "Usa os dois juntos para poder matar os peixes grandes do lago. Alguns lagos são mais fundos e alguns mais secos. E aquele timbó mais fino é usado no igarapé e lagos pequenos com pouca água. Os peixes pequenos estão no igarapé" (ANCIÃO 1, 2015).

O timbó é um cipó trepador encontrado nas mais diversas regiões brasileiras, em especial na região amazônica, também conhecida como tingui, guaratimbó, timbosipo, timbóiurari, cururu-apé, mata-fome, entre outros; considerado venenoso, contém uma toxina capaz de asfixiar e matar peixes em poucos minutos (TXICÃO, 2016). Ainda segundo o autor, diversos estudos asseguram que o timbó além de ser tóxico aos animais de sangue frio também o é ao homem, outras pesquisas afirmam que não causam mal algum ao ser humano.

A pescaria com o timbó, também conhecida como tinguijada, de uma maneira geral, é a pesca onde corta-se o cipó em pedaços, faz-se diversos emaranhados e amarra-se. Em seguida macera-se o timbó, ou seja, os emaranhados são colocados sobre uma superfície dura e golpeados por diversas pancadas de algum pedaço de madeira, por fim são passados na água, o processo se repete inúmeras vezes (TXICÃO, 2016). A partir daí o trabalho realizado é o de apanhar os peixes que estão atordoados ou mortos e boiando. De maneira mais específica, a pescaria com o timbó pode ser feita de três maneiras, que serão descritas a seguir.

A primeira forma é praticamente realizada em grandes rios, geralmente nas estações de águas baixas, ou seja, em rios calmos. Consiste basicamente em lançar o timbó a partir de um determinado local do rio para a seguir fazer-se a coleta dos peixes entorpecidos num outro trecho, no sentido em que correm as águas.

A segunda, é a utilização do timbó em igarapés, geralmente os índios atraem os peixes para dentro destes locais com iscas, que são lançadas no dia anterior à tinguijada, fecha-se então a foz do igarapé de noite com um pari. No dia anterior, introduz-se o timbó macerado na cabeceira do igarapé, para posteriormente efetuarem a coleta dos peixes entorpecidos com um puçá.

\section{PROCEDIMENTOS METODOLÓGICOS}

Este estudo aproxima-se de uma pesquisa etnográfica, cuja abordagem é qualitativa. A etnografia pode ser entendida como um estudo da cultura e das pessoas no seu próprio ambiente, mediante entrevistas e observações participantes (GIL, 2010). Para Neves (1996, p. 2), "os métodos qualitativos trazem como contribuição ao trabalho de pesquisa uma mistura de procedimentos de cunho racional e intuitivo capazes de contribuir para a melhor compreensão dos fenômenos". 
Seu desenvolvimento ocorreu durante os anos de 2014, 2015 e 2016 e investigou o povo Tapira da terra indígena Urubu Branco, localizada nos municípios de Santa Terezinha, Porto Alegre do Norte e Confresa/MT. Essa investigação é sobre a pesca com timbó, um tipo de pesca artesanal utilizada pelo povo Tapirapé desde os antepassados.

Para investigar como o povo Apyãwa realiza a pesca artesanal com o timbó, foram seguidos alguns procedimentos. Inicialmente foi realizada uma entrevista com moradores na minha aldeia. Optou-se pelo mais velho para relatar nossa cultura, até mesmo para que não desapareça os contos de nossos ancestrais. É preciso valorizar nossos costumes e registrá-los por meio de escritos, para que as crianças e os jovens saibam e preservem nossa cultura.

Essa pesquisa foi realizada na aldeia Tapiparanytãwa (córrego da onça), onde foi entrevistado o ancião Makapyxowi José Antônio Tapirapé, de 69 anos de idade, morador dessa aldeia (um dos moradores mais velhos) e grande narrador da história Tapirapé.

Depois foi vivenciada a pesca coletiva com timbó, além das pesquisas sobre o assunto. Em seguida, foi analisada a explicação dada pelo entrevistado e relacionado com os momentos da pesca, assim foi possível produzir o texto, ao qual foram inseridas imagens que serviram para ilustrar todas as etapas dessa importante prática.

\section{A PESCA COM TIMBÓ DO POVO TAPIRATÉ}

Algumas regras sobre a pesca com timbó são: "Primeiro o dono de pesca com timbó aconselhou todas as pessoas que vão participar essa pesca. Então a pessoa que vai participar não pode fazer nada sexo antes se não o peixe não morre com essa pesca. Se a pessoa fizer o sexo e ir lá na pesca com timbó, ele pode vai limpar automaticamente todo o espírito de timbó. É porque o timbó tem o espírito próprio dele, ele não gosta disso, assim, ele vai se limpando automaticamente e o peixe não morre coisa nenhuma" (ANCIÃO 1, 2015).

Também tem outra regra: "Quando o peixe começa ficar tonto, e o pessoal não pode cair na água com ele, se caiu para ele na água ele pode morrer somente no fundo do lago, por isso que temo espera ele chegar em até na beira do lago, e o peixe morre em beira do lago mesmo e mais faço para recolher o peixe. Quando caiu para ele e o peixe vai a fundar e vai morrer no fundo do lago, e não vai boiar agorinha mais não, só vai boiar quando vai ficar podre agora. Isso é outra regra da pesca com timbó" (ANCIÃO 1, 2015).

Sobre a participação das crianças o Ancião 1 (2015) afirmou: “A criança chega na pesca com o timbó sempre acompanha o seu pai ou mãe. Porém, antes de chegar no rio, a criança já deve ser instruída por seus pais que lhes ensinam e dão conselhos, isso porque a pesca com timbó tem suas regras, além de ser muito perigosa". 
Um exemplo dos perigos envolvidos são os peixes que têm esporão, por isso que criança temo cuidar com isso também, até mesmo porque a criança chega assim com tudo sem medo de nada. Outro ensinamento é referente como que se matam os peixes, as crianças aprendem tudo isso sobre a pesca desde pequenos. Na Figura 2 é ilustrado o envolvimento de todos durante a pesca, mas sempre observando as regras e costumes do povo tradicional.

Figura 2: Envolvimento de crianças e mulheres

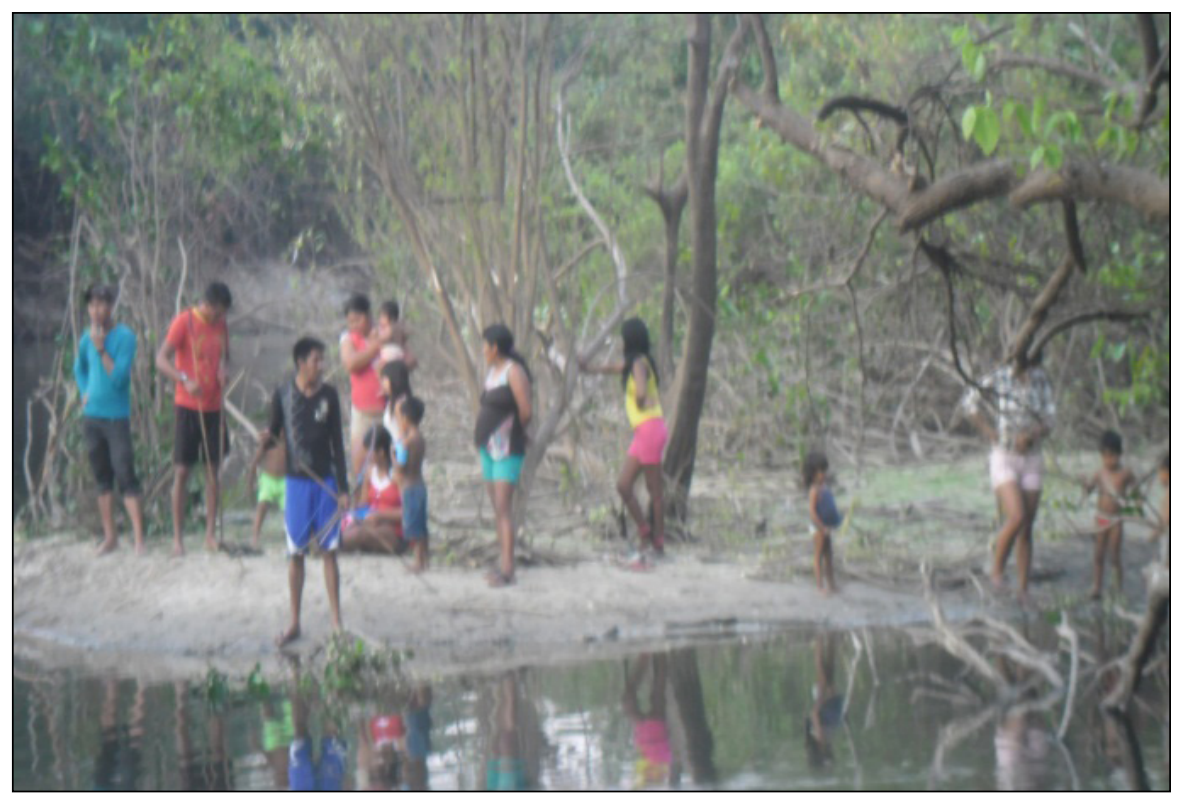

Fonte: Acervo pessoal do pesquisador (2014).

Porém, antes disso ocorrer, a orientação para os adultos iniciarem a pesca é a seguinte: "Ante de bater tem que procurar os lagos e igarapés onde que tem muito peixe e bom para fazer a pesca de timbó. O cipó timbó somente encontrada no mato também, ela se rola na madeira subindo até no fim da altura dela" (ANCIÃO 1, 2015). Os dois tipos de timbó encontrados na comunidade são o grosso e o fino (Figura 3). 
Figura 3: Cipó grosso (esquerda) e cipó fino (direita)

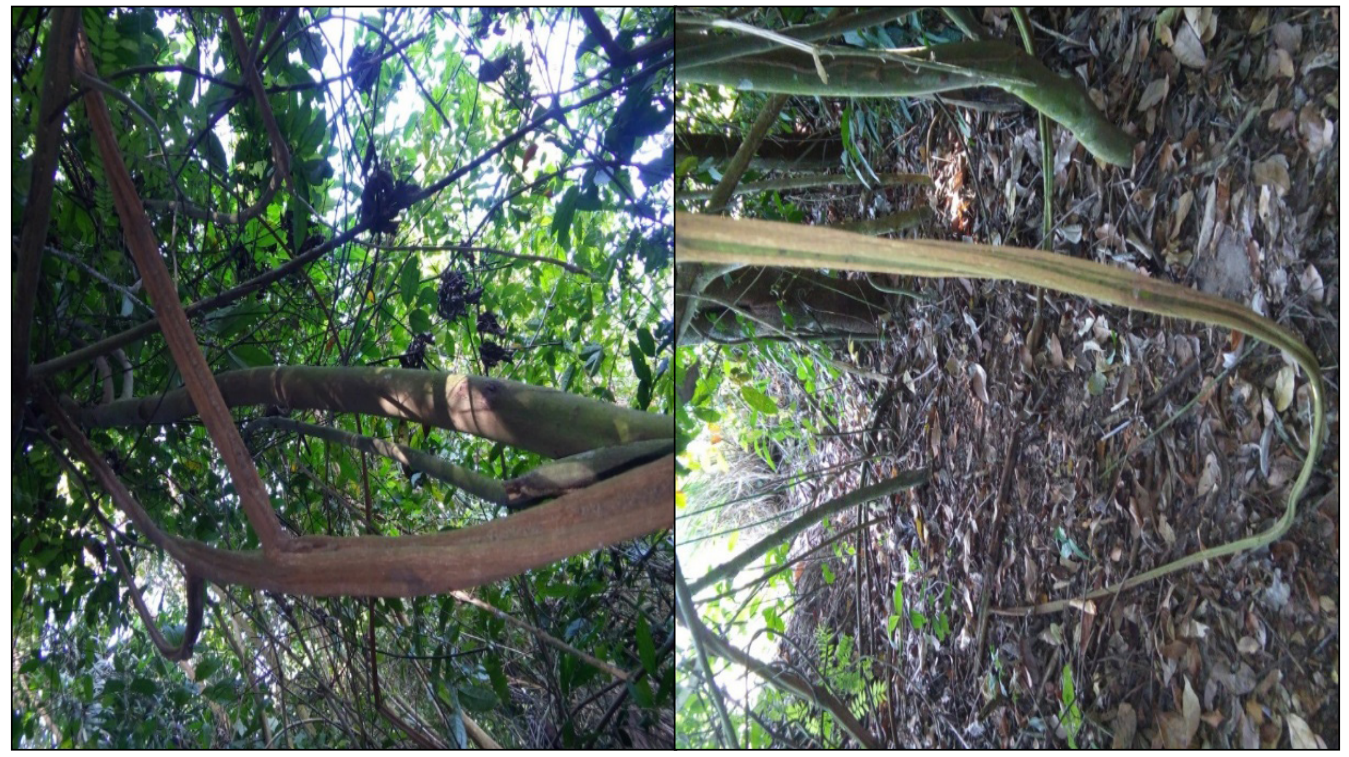

Fonte: Acervo pessoal do pesquisador (2016).

Outra pergunta foi: Como o povo Apyãwa organiza a pesca com o timbó? "Antes de acontecer o momento de coletar a raiz os homens Apyãwa não podem fazer nada; não pode nem acontecer o sexo, tem que respeitar a cultura tradicional, por que não é permitido o homem fazer sexo antes de praticar timbó" (ANCIÃO 1, 2015).

Ainda segundo o entrevistado, tem a época certa para coletar o timbó no tempo de inverno é bom é por quer os lagos e igarapés vão ficar seca também. O caule desse cipó é bom para bater, pois libera um líquido que mistura na água e é por isso que os peixes vão correr. Na figura 4 é observado como o timbó é coletado. 
Figura 4: Como o timbó é coletado

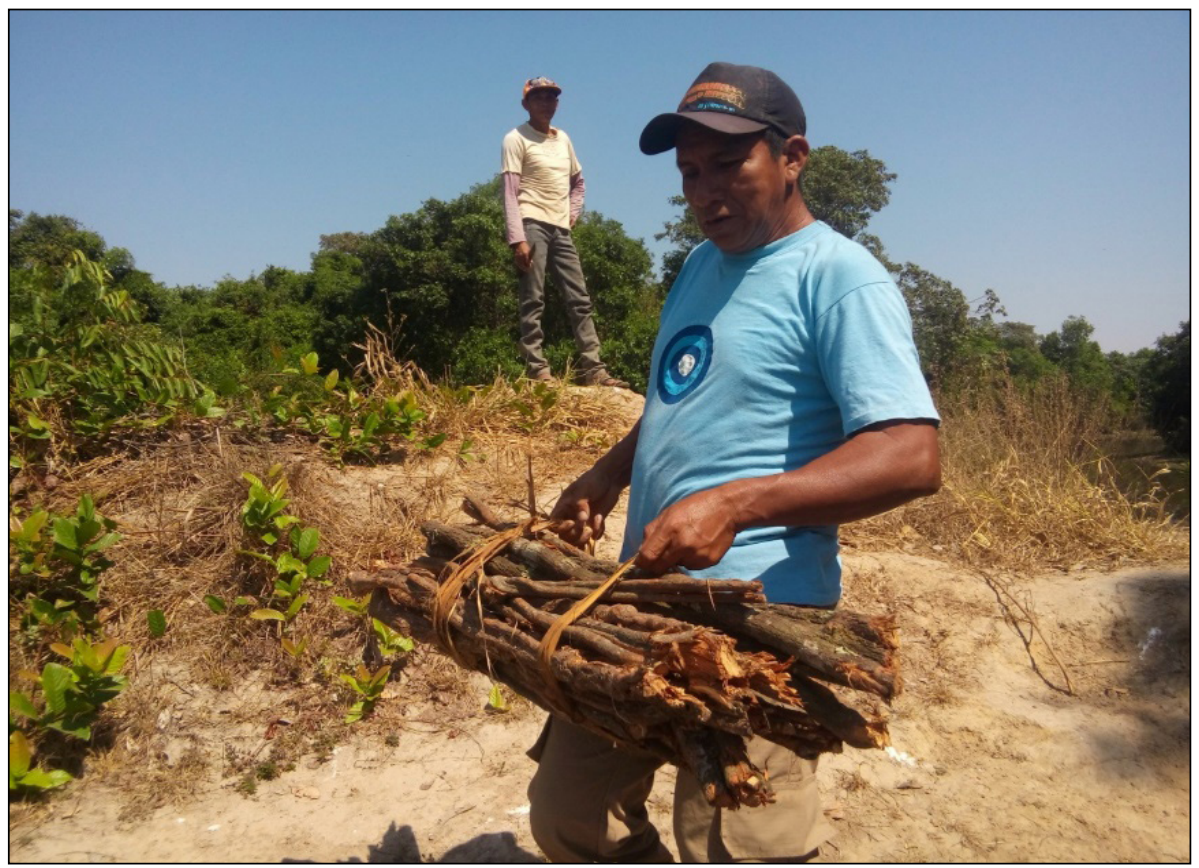

Fonte: Acervo pessoal do pesquisador (2015).

Sobre como os homens utilizam o caule para matar peixe no lago ou nos igarapés, o entrevistado contou que a primeira coisa é procurar o lago que tem peixe e onde tem muito peixe. Segundo as próprias palavras do entrevistado: "Nesse momento os homens Apyãwa se reúnem, convidando todas as pessoas para participar de ximaãzwa, que é a pescaria de timbó" (ANCIÃO 1, 2015). Quando os homens vão em busca do timbó no mato ou até mesmo para bater o timbó no lago (conforme Figura 5), eles calculam a quantidade do timbó baseando no tamanho do lago.

Esse timbó coletado somente pode ser batido pelos homens, ou seja, não é permite para mulheres baterem xigy. "Todos os homens são aconselhados por chama antes de bater o timbó, por que ele é a chefia que comanda neste momento. Então, quando ele libera, os homens caem na água para bater timbó e já canta a música no ritual timbó. Alguns vão de yãpewa (canoa), que é construída de madeira seca, para bater o timbó no meio do lago e os outros vão beirando a margem do lago" (ANCIÃO 1, 2015). 
Figura 5: Homens batendo o timbó

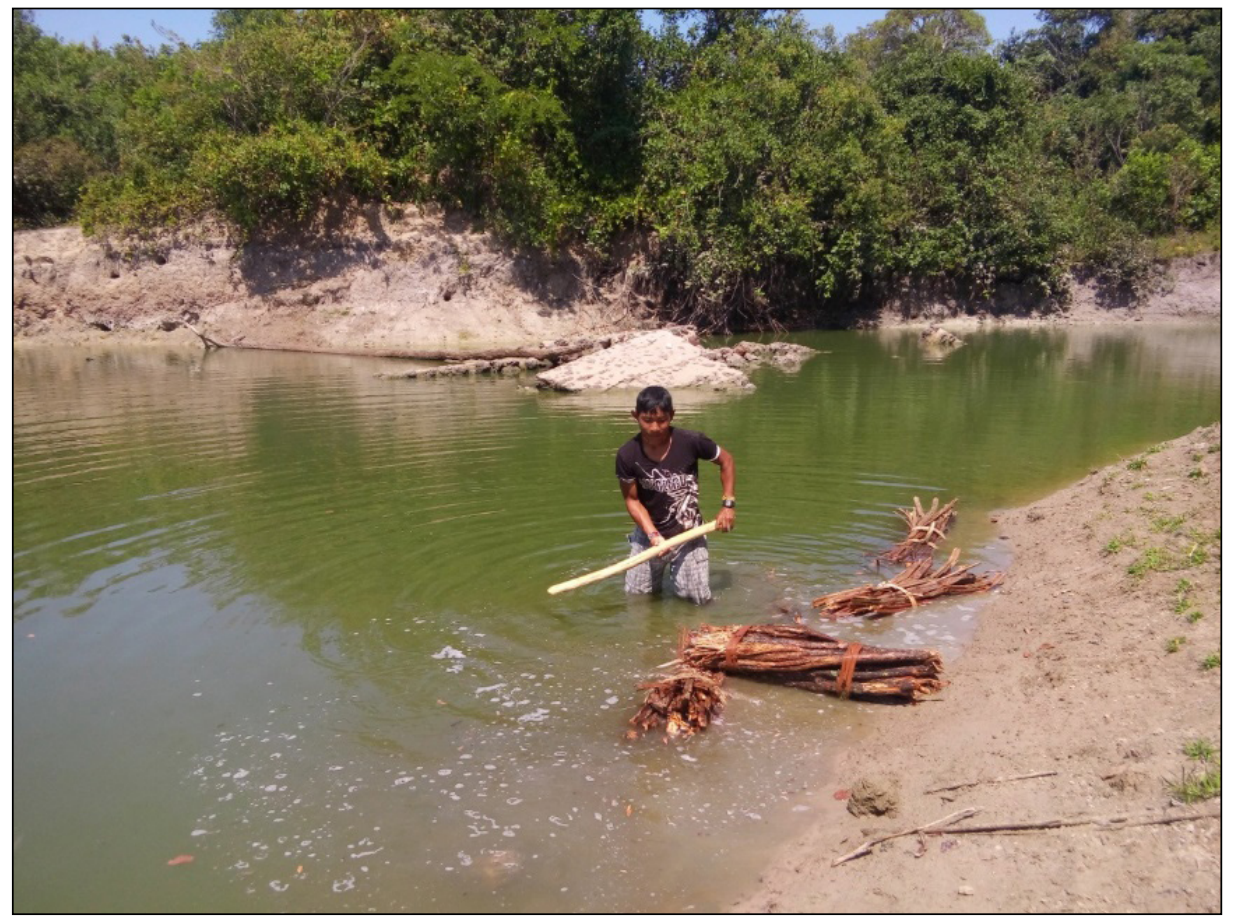

Fonte: Acervo pessoal do pesquisador (2015).

E logo-logo o peixe vai boiar, dali uns 15 minutinhos, e mulheres somente podem participar nesse momento, na hora de recolher o peixe. Assim, todos participam. A mulher também é responsável por preparar a farinha de puba que acompanha o peixe assado e que servirá para ser consumida pelos homens na pescaria com timbó na beira do lago. Cada família vai acampar na beira do lago se organiza para assar os peixes que vão sendo pescados, por que eles ficam acampados mais ou menos dois dias.

Desse mesmo jeito outros vão no outro lado do lago para todos irem batendo de igual para igual, de ponta a ponta no lago. Quando os homens acabam de bater o timbó, depois de terminar, eles saem e vão para a beira do lago à espera do peixe ficar tonto, que chamamos de ipirãka'o. Nesse momento ninguém fazer barulho. $\mathrm{O}$ momento dessa espera silenciosa pode ser observado na Figura 6. 
Figura 6: Momento de espera para os peixes flutuarem



Fonte: Acervo pessoal do pesquisador (2015).

Outra característica a ser considerada é que também tem época certa para coletar o timbó. No inverno (estação seca na região centro-oeste) é o período ideal, isso porque os lagos e igarapés vão ficar secos também. Esse momento é bom para bater porque os peixes vão ficar mais fáceis de serem coletados.

Quando as pessoas capturam muitos peixes na pesca com timbó, o entrevistado disse que o trabalho em equipe que foi o responsável, além da permissão do espírito dos lagos. "Eles utilizam flecha, facão, rede e outros para recolher os peixes da água enquanto as mulheres vão lembrar de fazer farinha de peixe. Então o genro, nesta parte, trabalha bastante assando peixe ou então o sogro trabalha assando o peixe" (ANCIÃO 1, 2015).

Uma das espécies coletadas é o jaraqui, que na língua materna se chama ywyxao. Esse peixe pode ser observado na Figura 7. 
Figura 7: Jaraquis capturados durante a pesca com timbó

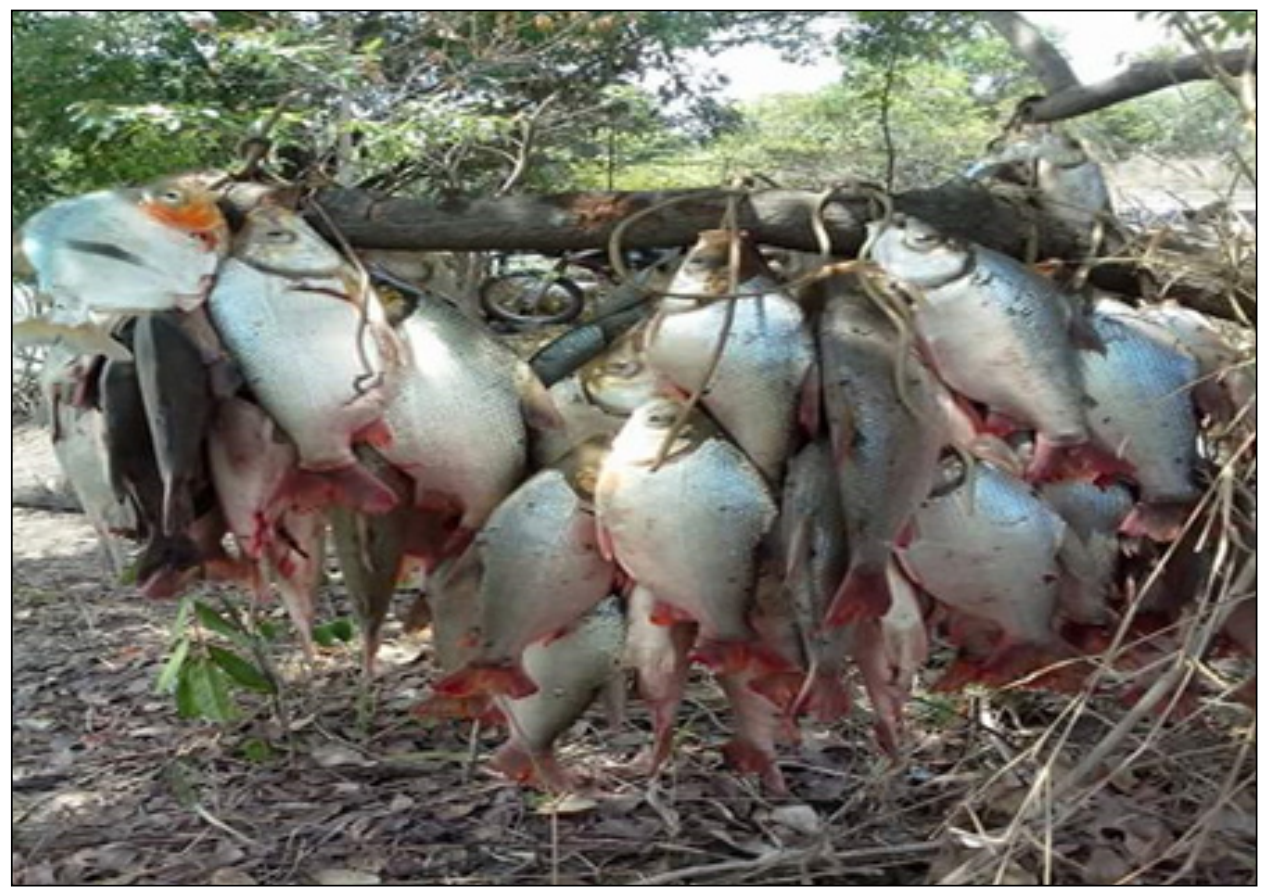

Fonte: Acervo pessoal do pesquisador (2015).

O povo Tapirapé captura mais o peixe que chama de jaraqui na pesca com timbó. Qualquer pesca com timbó o peixe que mais morre é jaraqui mesmo, porque em qualquer lugar (rios ou igarapés) tem jaraqui. Esse tipo de peixe é comum na região e pode encontrada nos rios e nos lagos.

Para o povo Apyãzwa, após a pesca com o timbó, o pessoal tem costume de comer o peixe com farinha, cará, macaxeira, batata e também levam alimentos ocidentais. Os peixes são bastante apreciados na alimentação dos Tapirapés. O preparo pode ser observado na Figura 8. 
Figura 8: Preparo dos peixes

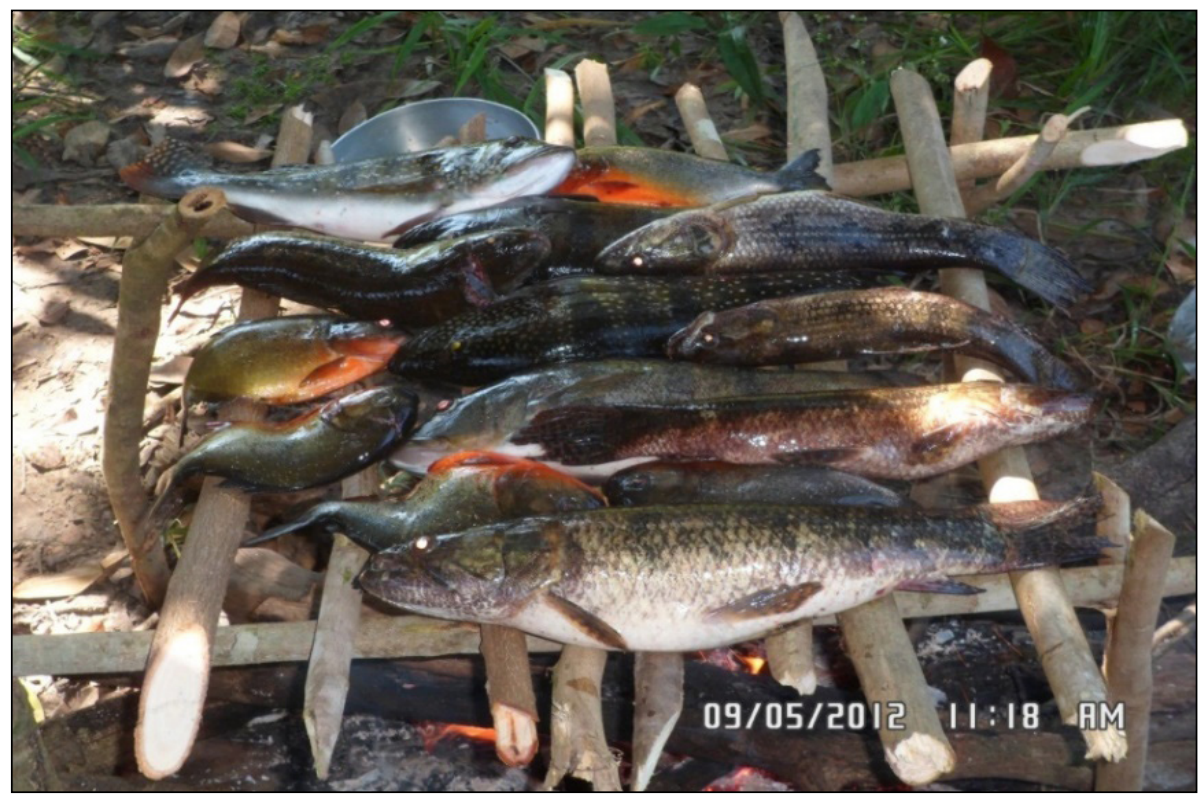

Fonte: Acervo pessoal do pesquisador (2012).

O povo Tapirapé aproveita todos os peixes que morrem na pesca com timbó. Eles prepararam como assado, cozido, fazer farinha de peixe e mimakeka também. O povo Tapirapé prepara mais o peixe, como farinha do peixe mesmo, para durar mais tempo ainda deixando conservando, essa farinha de peixe pode deixando conservando a um ano que foi estragando.

Na pesca com timbó povo Tapirapé mataram em qualquer tipo de peixe, seja pequeno, seja peixe grande. E mesmo que o povo Tapirapé matou muito peixe, e ainda deixou muitos outros peixes no rio.

\section{CONSIDERAÇÕES FINAIS}

O presente artigo visou, de forma breve, expor as principais informações que dizem respeito a pesca indígena dos Tapirapés com o uso do cipó timbó em água doce. É preciso esclarecer que o timbó é um cipó que contém toxinas capazes de impedir a respiração dos peixes. Sempre que realizada, essa prática cultural tem o intuito de obter alimentos para as famílias da comunidade tradicional.

A pesquisa foi importante para registrar as regras e as etapas da pesca coletiva com timbó. Além de proporcionar o registro das etapas da pesca com o timbó, o estudo permitiu registar essa prática milenar de nosso povo que ainda são valorizadas e resistem, além de descrever as regras envolvidas na pescaria. 
A pesca só ocorre no período de seca, quando a água está no nível baixo. O povo Apyãzwa utiliza dois tipos de cipó juntos para capturar peixes, que são eles: o ximaõna, um cipó grosso e da casca preta; e o ximakyra, timbó fino e com a casca verde.

Quando é grande a captura de peixes, acredita-se que foi devido ao espírito do lago permitir e porque o povo Apyãwa fez um trabalho em mutirão. Todo peixe que morre com a pesca é aproveitado na alimentação. Ainda hoje esse povo tradicional realiza essa prática para coletar alimento. O peixe é assado num pequeno jirau.

Portanto, foi importante registrar como é realizada esse tipo de pesca artesanal pelo povo Tapirapé, assim como são os costumes e regras deixadas pelos antepassados para que as gerações futuras possam fortalecer a cultura. Espera-se que esses costumes sejam cada vez mais conhecidos e respeitados pelo não indígena, ao mesmo tempo que utilizadas pelas gerações futuras de nosso povo.

\section{REFERÊNCIAS}

GIL, Antônio Carlos. Como elaborar projetos de pesquisa. 5. ed. São Paulo: Atlas, 2010.

ISA - Instituto Socioambiental-Instituto Socioambiental. Povos Indígenas no Brasil:1991-1995. São Paulo, Brasil, ISA, 1996: 871.

NEVES, J. L. Pesquisa Qualitativa - características, usos e possibilidades. Caderno de Pesquisas em Administração, São Paulo. V. 1, No 3, $2^{\circ}$ Sem/1996. Disponível em: <http://www.unisc.br/portal/upload/com_arquivo_qualitativa_caracteristicas_ usos_e_possibilidades.pdf >. Acesso em: 12 jul. 2016.

OLIVEIRA, A. R. De plantas, peixes e parentes: Técnica e cosmologia no debate sobre a pesca do timbó entre os Wapichana na região Serra da Lua, Roraima. Brasília: EdUnB, 2015.

SILVA, M. W. Diversidade cultural dos povos Indígenas. 2012. Disponível em:www. progresso.com.br/opiniao/wilson-matos/diversidade-cultural-dos-povos indígenas. Acesso em 02 de agosto de 2016.

TXICÃO, K. A pesca dos Ikpeng com cipó timbó-açu (Sapindácea): Aspectos da cultura e da ciência na relação com o meio ambiente. 2016. (Trabalho de Conclusão de Curso). Licenciatura Intercultural Indígena em Ciências Matemáticas e da Natureza. UNEMAT. Barra do Bugres-MT, 2016. 